\title{
A PRÁTICA DO(A) SELFIE E MODOS DE SUBJETIVAÇÃO NA CONTEMPORANEIDADE
}

\author{
Gesualda dos Santos Rasia** \\ Universidade Federal do Paraná \\ Setor de Ciências Humanas \\ Curitiba, PR, Brasil
}

\begin{abstract}
Resumo: $O$ estudo, filiado à AD francesa, ocupa-se com a injunção contemporânea à visibilidade, agudizada pela dimensão virtual. Para refletir sobre os modos como se tece o chamado à exposição do eu, partimos do(a) selfie feito(a) por uma moça, sorrindo, no velório do presidenciável Eduardo Campos, ao lado do caixão deste, em agosto de 2014, fato de repercussão negativa à época. Este acontecimento é posto em relação com outros, de natureza semelhante, porém, de escopos diferenciados, como mote para a discussão central do estudo: como se (re) configuram hoje as formas de subjetivação, diante do que entendemos como desistoricização da memória. A discussão teórica desenvolvida faz convergir três dimensões atinentes à prática do(a) selfie, suscitadas pelos episódios tomados como motivadores do debate: a dimensão linguística, enquanto materialidade histórica; a antropológica, enquanto prática assumida por sujeitos socialmente inscritos; e a política, porque revestida de sentidos e perpassada pela ideologia.
\end{abstract}

Palavras-chave: Subjetivação. Memória discursiva. In(visibilidade). Selfie.

\section{INTRODUÇÃO}

Três episódios com, minimamente, um ponto de convergência: a produção do(a) selfie. Um deles, o realizado no velório do então presidenciável Eduardo Campos, gerou indignação nas redes sociais. O realizado na exposição "Gênesis", redundou na bemfundamentada indignação do próprio envolvido: o fotógrafo Sebastião Salgado: "Há seis meses, eu abri uma exposição e as pessoas vinham conversar comigo, pediam um autógrafo, trocavam ideias. Agora acabou. Cada pessoa te agarra e quer tirar selfie", desabafou em reportagem constante na Folha de S.Paulo. Já o terceiro, trata-se daquele praticado (ou sugerido que seja praticado) por casais, na Pont Des Arts, em Paris, em virtude do problema que o peso dos cadeados, costumeiramente colocados no arco da ponte, está causando à sua estrutura.

Os eventos midiáticos são assumidos enquanto motes, conforme já dito, porque representativos de um modo de ser. Assim, o trajeto teórico-analítico circunscreve as condições históricas mais amplas nas quais emerge a prática do(a) selfie e também atenta a particularidades relativas à questão do gênero e da agentividade da designação,

\footnotetext{
* Trabalho apresentado, em uma primeira versão, no II SEPLEV - Seminário de estudos em práticas e espaço Virtual, realizado na Universidade Federal de Pernambuco, Recife, de 19 a 21 de novembro de 2014.

** Professora, Doutora em Letras pela UFRGS. E-mail: gesualdarasia@yahoo.com.br
} 
buscando pontos de encontro da língua com a história. Ainda, seu caráter de repetibilidade, desvestido de significação, é colocado em relação à noção de memória discursiva, a partir do que é possível se pensar como os sujeitos respondem às demandas contemporâneas de nossa Formação Social.

Fica posta em pauta, a partir dos três fatos recortados e de seus respectivos desdobramentos, uma questão que diz respeito aos modos de subjetivação na contemporaneidade, cortada e diluída pela fragmentação. Fragmentação essa que é olhada desde uma perspectiva discursiva, no afã de se entender o paradoxo da (in)visibilidade, trazendo, para a conversa com a Análise do Discurso pêcheuxtiana, o que Vargas Llosa (2013) designou de "A civilização do espetáculo" e o que Nicole Aubert e Claudine Haroche (2011) explicitaram como "injunção à visibilidade".

\section{SOBRE AS CONDIÇÕES DE PRODUÇÃO DOS ACONTECIMENTOS QUE CIRCUNSCREVEM O(A) SELFIE COMO MODO DE SER DA CONTEMPORANEIDADE}

Orlandi (2009a) distingue a categoria condições de produção em sentido amplo, referindo-se ao contexto sócio-histórico-ideológico, e em sentido estrito, quando se trata das circunstâncias de enunciação. Inicialmente, abordaremos, aqui, as condições de produção imediatas, ou em sentido estrito, porque diretamente relacionadas à emergência histórica da enunciação.

O primeiro caso, realizado por uma moça no velório do político Eduardo Campos, ao lado de seu caixão em agosto de 2014 , no auge da campanha para a sucessão presidencial no Brasil ${ }^{1}$, desenhou indícios midiáticos de uma suposta ascensão da então presidenciável Marina Silva, assim como de uma possível reconfiguração da posição do candidato Aécio Neves. Em que pesem os sentidos humanos da morte, a dimensão política falou mais forte no espaço publicável, razão por que o momento mínimo em que as câmeras captaram um sorriso da candidata Marina Silva, tornou-se sintagma nominal nas redes sociais: "O sorriso de Marina". Os demais também riam, de algo ou de alguém, mas apagou-se o contexto e o entorno, e levantaram-se pressupostos. A mídia permaneceu atenta, pois o momento era decisivo para o país, e qualquer gesto significava. Não se tratava de considerar o riso na perspectiva do desrespeito, como seria comum, no caso de qualquer velório.

Diferente foi o caso do(a) selfie da moça sorrindo, ao lado do caixão, e que circulou sobejamente nas redes sociais, gerando matérias também em jornais impressos, em um deles sob o título "Selfie em velório de Eduardo Campos gera indignação nas redes sociais" (Jornal O Globo, 17/08/2014).

Cidadã comum, não havia interesses de estado em jogo. Era somente mais um anônimo na multidão querendo "aproveitar a deixa" para registrar seu momento com uma celebridade. Ainda que morto. $\mathrm{O}$ que restava posto em causa, e que, na sequência, discutiremos: os limites entre público e privado, entre outros aspectos.

\footnotetext{
1 O registro do(a) selfie está disponível no site <http://oglobo.globo.com/brasil/selfie-em-velorio-decampos-gera-indignacao-nas-redes-sociais-13635476>.
} 
No segundo caso, cujo personagem central é Sebastião Salgado, capturado em segundo plano, olhando para baixo, por uma moça de olhar vivaz ${ }^{2}$, atentemos para a análise que o fotógrafo faz sobre o fato em depoimento à mídia. Indignado, ele produz, em sua fala, um efeito de datação para a prática do(a) selfie: "Há seis meses atrás...". Considerando-se que a matéria foi publicada em setembro de 2014, a exposição a que Salgado se refere aconteceu em março. Que a era tecnológica que vivemos nos oferece novidades em ritmo acelerado é algo posto e sabido. Que estamos na era da imagem e da injunção à exposição do eu, do mesmo modo. Mas a prática do(a) selfie, de modo peculiar, comporta em si alguns traços que agudizam essas duas dimensões, porque tem a ver com as diferentes formas como os sujeitos se subjetivam na contemporaneidade. Portanto, esta é pauta que interessa sobremaneira à Análise do Discurso de vertente pêcheuxtiana.

E quanto ao terceiro caso, o dos cadeados da Pont des Arts, em Paris? Notícia do site Uol registra que no dia 8 de junho de 2014 uma parte do alambrado da Ponte desabou, muito provavelmente devido ao excesso de peso das dezenas de cadeados do amor, presos a ela desde 2008, por turistas. O(a) selfie surge, então, não como opção primeira dos visitantes enamorados, mas prática substitutiva, determinada pela Prefeitura de Paris na tentativa de preservação da ponte. Sites da internet ostentam inúmeras imagens com selfies feitas nesse lócus; uma delas, posterior à determinação da Prefeitura, mostra duas moças orientais registrando um momento romântico ${ }^{3}$. Tal determinação coloca-nos diante de uma questão, dentre outras, e não desvinculada daquelas anteriormente postas: quais os limites de interferência da esfera pública na privada, especialmente quando essa interferência diz respeito aos modos como as pessoas podem construir/constituir seus modos de subjetivação?

\section{A GRAMATICALIZAÇÃO DA DESIGNAÇÃO SELFIE, AS DISPUTAS DE SENTIDOS NA ORDEM DA LÍNGUA E O ENTRELAÇAMENTO COM A SUBJETIVIDADE}

Para se pensar essa prática novidadeira que se insere na história, entendemos ser interessante principiar pela designação, de matriz americana. Um aspecto a considerar é a oscilação na marcação do gênero. Para tanto, recorremos, inicialmente, à dicionarização da palavra em questão. E, vale dizer, como analista de discurso que somos, inscrevemonos em uma perspectiva que concebe os dicionários como "objeto discursivo". Horta Nunes (2010, p. 6-7) assim explicita essa concepção:

\footnotetext{
Em primeiro lugar, significa que o dicionário não é algo que estaria na mente das pessoas desde que elas nascem, mas, sim, algo que é produzido por práticas reais em determinadas conjunturas sociais, ou seja, o dicionário é produzido sob certas condições. E as palavras não são tomadas como algo abstrato, sem relação com os sujeitos e as circunstâncias em que eles se encontram, mas sim como resultantes das relações sociais e históricas, relações essas que são complexas e, por vezes, polêmicas ou contraditórias. Assim, o dicionário é visto como um discurso sobre a língua, mais especificamente sobre as palavras ou sobre um setor da realidade, para um público leitor, em certas condições sociais e históricas.
}

\footnotetext{
${ }^{2} \mathrm{O}$ registro do (a) selfie consta no endereço <http://www1.folha.uol.com.br/ilustrada/2014/09/1517385selfie-e-agressao-permanente-diz-sebastiao-salgado.shtml>.

${ }^{3}$ Imagem disponível em: <http://noticias.uol.com.br/internacional/ultimas noticias/2014/08/11/>. Acesso em: 30 out. 2014.
} 
A versão digital da revista Veja, de 23 de novembro de 2013, registrou anúncio acerca da emergência da dicionarização do vocábulo representativo da nova prática de relacionamento, nas páginas de um importante dicionário:

\begin{abstract}
Na última quarta-feira, o respeitabilíssimo Dicionário Oxford, o mais extenso da língua inglesa, anunciou que um novo verbete passaria a figurar em suas páginas: selfie, que reúne o substantivo self (eu, a própria pessoa) e o sufixo ie. Eis sua definição: "Fotografia que alguém tira de si mesmo, em geral com smartphone ou webcam, e carrega em uma rede social." Os responsáveis pelo Oxford informaram que o dicionário surgido no século XIX aceitou o novo verbete porque as citações a selfie cresceram $17.000 \%$ neste ano mensalmente, um programa coleta mais de 150 milhões de palavras em publicações variadas e analisa a recorrência delas. O ingresso do termo no Oxford, no entanto, não é apenas fruto de uma estatística. É o reconhecimento de um fenômeno global. Tornou-se um gesto comum esticar o braço segurando o celular apontado para o rosto, e depois compartilhar a foto no Instagram, Facebook ou similares. O selfie pode revelar um estado de espírito ou ser um meio de autopromoção $[. . .]^{4}$
\end{abstract}

Atentemos para a linearização do verbete:

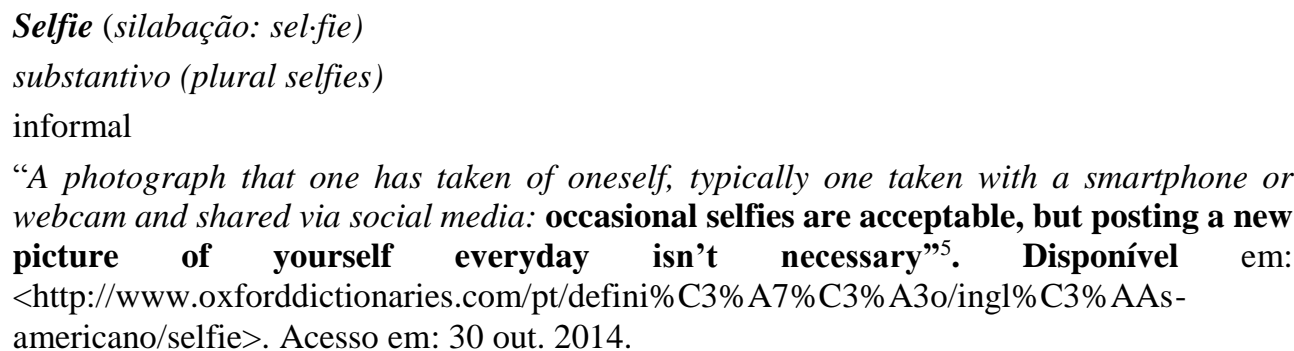

Observe-se que o Dicionário Oxford não determina a marcação de gênero, não parecendo a variável normativa uma preocupação, ou talvez seja justamente a oscilação no uso que resulte na omissão quando do registro. De outra parte, há uma preocupação em propor alguma orientação no que concerne à mediação entre os sujeitos e a prática do selfie. Essa assunção, de ar pedagógico, soa minimamente estranha, no escopo de um dicionário.

Já no Dicionário Priberam, da Língua Portuguesa, o(a) selfie consta como sendo palavra feminina:

\author{
selfie \\ (palavra inglesa) \\ substantivo feminino \\ [Informal] Fotografia que alguém tira a si mesmo, geralmente para publicação
}

\footnotetext{
4 Disponível em <http://veja.abril.com.br/noticia/vida-digital/selfie-e-nova-maneira-de-expressao-eautopromocao/>. Acesso em: 25 nov. 2013.

5 Tradução livre: Uma fotografia que alguém tirou de si mesmo tipicamente feita com um smartphone ou webcam e compartilhada via mídias sociais: selfies ocasionais são aceitáveis, mas postar uma nova foto de você mesmo todos os dias não é necessário.
} 
em rede social. $=$ AUTORRETRATO

Plural: selfies. ${ }^{6}$

Em que pese essa oscilação, o seu uso tem se cristalizado, hegemonicamente, no português brasileiro, com o determinante masculino. Enquanto a palavra em si manteve todos os traços mórficos no processo de importação, o gênero oscilou, o que é compreensível, se considerarmos que essa marcação é regulada por princípios que são da ordem da arbitrariedade. Neste estudo, optamos por marcar a referida oscilação, pelo fato de que ela significa na história, enquanto processo de sedimentação do sentido. Outro aspecto que pode ser destacado é como o substantivo assume estatuto de ação, o que se dá, no mínimo, de três modos diferentes: "fazer um(a) selfie", "tirar um(a) selfie" e "posar para o(a) selfie". Contudo, os verbos que compõem os sintagmas que dão ideia de ação nos apontam para algo minimamente interessante: os verbos fazer e tirar, se considerado o campo semântico de fotos (lembrando de práticas antigas), podem remeter tanto ao agente quanto ao paciente-alvo da ação, mas isso de modo excludente. Já o verbo posar reporta apenas o alvo da ação. Contemporaneamente, contudo, agente e alvo podem coincidir com relação às ações de fazer/tirar fotos. E posar, por extensão, também. E disso decorre uma consequência para o campo gramatical. Pensemos, por exemplo, naquilo que a NGB designa como adjunto adnominal e complemento nominal no que diz respeito às funções sintáticas. No primeiro caso, ficam enquadrados os sintagmas que se referem a substantivos de caráter agentivo, enquanto que no segundo, enquadram-se os de caráter passivo no que concerne ao nome que a eles se refere. Ex:

a) A foto de Sebastião Salgado - a foto que Sebastião fez, enquanto fotógrafo. = adjunto nominal.

b) A foto de Sebastião Salgado - a foto que foi feita de Sebastião Salgado. = complemento nominal.

Essa distinção é problemática, tendo em vista, sobretudo, as dificuldades semânticas que este critério apresenta. E, no que se refere ao caso específico da designação selfie, a ordem da língua produz uma síntese que apaga efetivamente a distinção agente/paciente. Podemos pensar, neste caso, não em um simples efeito de representação da realidade, mas no modo como as práticas históricas produzem transformações na linguagem enquanto prática humana, e por isto mesmo designada de ordem da língua, em distinção à organização da língua, princípio este que leva Orlandi (2009b, p. 18) a estabelecer as noções de língua imaginária e língua fluida, conforme segue:

\begin{abstract}
A língua imaginária é a língua sistema, a que os analistas fixam em suas regras e fórmulas, em suas sistematizações, são artefatos (simulacros) que os analistas da linguagem têm produzido ao longo de sua história e que impregnam o imaginário dos sujeitos na sua relação com a língua. Objetos-ficção que nem por isso deixam de ter existência e funcionam com seus efeitos no real. São as línguas-sistemas, normas, coerções, as línguas-instituição, estáveis em sua unidade e variações. São construções. Sujeitas a sistematização que faz com que elas percam a fluidez e se fixem em línguas-imaginárias.
\end{abstract}

\footnotetext{
${ }^{6}$ Disponível em: <http://www.priberam.pt/dlpo/selfie>. Acesso em: 30 set. 2014.
} 
A língua fluida, em contrapartida, prescinde da distinção classificatória, posto seu funcionamento estar regulado não por princípios regulatórios da organização normativa, mas pela ordem do discurso, a qual prevê as injunções históricas, daí a não necessária simetria forma gramatical e representação na ordem do mundo.

Entendemos que a designação selfie põe em tela a disputa de sentidos travada no eixo do gênero gramatical. Palavra migrada para a língua portuguesa, pela via das importações tecnológicas que acompanham a ordem econômica, traz consigo uma gramática cujo vetor é o uso, uma vez que é filha de um tempo em que as práticas dos sujeitos são infinitamente mais velozes e efêmeras do que os instrumentos linguísticos.

No que concerne à não dicotomização entre o caráter agentivo e o passivo da palavra, muito mais do que um aspecto classificatório, ele apresenta-se como um dos lugares de encontro da língua com a história. Na materialidade da língua encontram-se os pontos que marcam a refração do sujeito, emblematicamente simbolizados na palavra que reporta tão somente a imagens: o selfie da moça no velório de Eduardo Campos foi feito por ela e com ela. Não furtou-se, porém, aliás, como era desejado, de chegar ao olharoutro, ainda que olhar de indignação. Instante de "celebridade" registrado na efemeridade das mídias quotidianas, sem maiores abalos políticos para a nação. Mas não de menor representação para a constituição subjetiva de quem o faz, tanto o é que vez ou outra a cena se repete, com pequenas alterações de circunstâncias.

\section{CHAMADO À VISIBILIDADE E AS FORMAS DE SUBJETIVAÇÃO}

Outra via possível para a investigação desse fenômeno contemporâneo é o recorte que ora fazemos, de natureza histórica e antropológica, para posteriormente dimensionarmos seu aspecto político-discursivo. Desse ponto de vista, reportamos o rastreamento que Gripp (2015) empreendeu acerca das interações sociais a partir de Goffman (1967) e Saville-Troike (2003). A autora afirma que "o conceito de imagem social é muito antigo e remonta à cultura oriental chinesa, estando relacionado às qualidades individuais e a entidades abstratas, tais como honra, respeito e estima." Nessa cultura, esclarece Saville-Troike (2003, p. 70),

\footnotetext{
a face é um construto complexo que provavelmente teve sua origem nos termos lian e mianzi, oriundos do chinês. Lian, que é semelhante à honra, refere-se ao caráter moral que é publicamente atribuído a um indivíduo e conferido pela sociedade. O termo mianzi está relacionado ao prestígio e à reputação, resultantes das conquistas do indivíduo. Assemelhase à ideia de algo que é obtido pelo esforço e pelo mérito da pessoa.
}

É a partir dessa imagem social chinesa como algo público que o sociólogo a definiu como "uma imagem pública negociada". Para ele, o indivíduo, como membro de uma sociedade, procura apresentar uma "fachada", ou melhor, uma imagem positiva de si próprio para ser aceito socialmente e, ao mesmo tempo, espera que seu interlocutor aceite essa imagem. Goffman (1967) emprega o conceito de face para referir-se a esse tipo de comportamento, que diz respeito a dois dos conceitos complementares, que são: o respeito pela própria imagem e a consideração com a imagem alheia. 
Ora, se considerado o mote da "encenação-representação social", encontraremos, aí, muitas possibilidades de aproximação com a perspectiva histórico-discursiva, a começar pela mobilização pêcheuxtiana de formações imaginárias - "quem sou eu" e "quem é o outro" para que eu me poste visualmente desse modo e assim pretenda perpetuar minha imagem e permanência no mundo. Contudo, podemos problematizar o ponto que toca a interface com o outro histórico. Primeiro, porque não se trata de uma autopreservação nos moldes do "não quebrar a cara", como poderia ser esperado sob determinadas perspectivas, antes, "dá-se a cara a tapa", a julgar-se pelos modos de assunção dos sujeitos em situações as mais inusitadas possíveis; ou, inversamente, tão prosaicas que não se imaginaria passíveis de registro fotográfico há pouquíssimo tempo. Segundo, porque a visibilidade excessiva do eu parece não estar voltada ao exame do olho que autoclica, mas do outro que vê; paradoxalmente instaurado pelo excesso de centralidade do eu que clica e que fica no primeiro plano da foto. E terceiro, porque a profusão de selfies evidencia a premência-necessidade de estabelecimento de um lugar de ancoragem-pertencimento para o eu que se autorretrata, em detrimento da situação pano de fundo fotografado. Lembremos, aqui, da reclamação de Sebastião Salgado.

Como entender esse funcionamento? Uma noção cara à $\mathrm{AD}$ francesa, que é a de Formação Social, pode no auxiliar. Trazida em Michel Pêcheux ([1975] 1988), entrelaçada à noção de Formação Ideológica (FI), pode ser compreendida a partir de uma leitura do marxismo já relido por Althusser (2003), noção esta que "designa uma sociedade específica, com articulação específica de modos de produção, um dos quais exerce um papel dominante". Nessa releitura, a essência da análise social passou a ser, em grande medida, o exame das formas como esses modos operam e se articulam dentro das sociedades e das ditas formações sociais. A imbricação das FIs à FS se dá pelo fato de que as Formações ideológicas, enquanto sistemas de ideias, materializam-se nas diferentes relações de poder/embate/confronto que se instauram em uma determinada Formação Social. Por conta disso, uma FS diz respeito aos modos de produção/organização social de determinada sociedade, em uma determinada época, enquanto as FIs dizem respeito aos sistemas de pensamento que dão sustentação a esses modos de produção, mas também de transformação. Pêcheux ressalta que o funcionamento da instância ideológica, no que tange à reprodução das relações de produção, opera-se pelo viés da interpelação, ou seja, o modo como cada indivíduo é "chamado" a "situar-se" no corpo social em um dado momento histórico, ou em uma dada Formação Social, seja ela escravagista, feudalista ou capitalista.

No caso da discussão em tela, somos chamados, contemporaneamente, a responder afirmativamente do lugar de quem tem posses para ter um aparelho que registra e exibe com qualidade seus eventos de ordem privada e que possam vir a se tornar objeto de desejo de outrem. Embora não nos demos conta, nessa intrincada teia, que estamos, nos termos de Pêcheux ([1975] 1988, p. 159), respondendo sim ao clássico enunciado ilustrativo: "se você é um verdadeiro soldado francês, o que, de fato, você é, então você não pode/deve recuar". Sob outras formas, mas o chamado se mantém. Na esteira do pensamento de Aubert e Haroche (2011), o qual pautaremos na sequência, está em causa a injunção à visibilidade, muito mais do que a injunção ao consumismo num efeito de planificação/homogeneização de faces e corpos, com efeito de apagamento dos abismos 
econômicos e sociais. A era tecnológica, em sua ordenança injuntiva, não impõe questões acerca dos lugares de patrão e empregado, conforme propunha o marxismo clássico, mas sobre quem aparece e quem não aparece, gerando uma reordenação ou mesmo opacificação da divisão de classes sociais e dos antagonismos que daí decorrem. Aparentemente, todos estão ou podem estar visíveis na rede mundial. O que parece distinguir os sujeitos são os ícones a que cada um se reporta.

Miremos, portanto, as formas como se constroem tais referências. Para além das situações até aqui descritas, os contextos de turismo, em que lugares emblemáticos e grandes monumentos praticamente não aparecem em postagens nas redes sociais. $\mathrm{Ou}$, quando aparecem, estão em segundo plano. Muitas vezes, deles temos conhecimento pelos títulos das postagens. O que se sobrepõe é a imagem do eu que posta, obliterando esses monumentos. É a imagem do agente-paciente da foto. Sujeito-objeto que, nessa tentativa de registro de sua passagem efêmera pela história, acaba por desistoricizá-la. Falemos disso, na próxima seção.

\section{O(A) SELFIE E A DESISTORICIZAÇÃO DA MEMÓRIA}

A memória discursiva, noção cara à AD, é distinguida por Courtine ([1981] 2009, p. 105) da memorização psicologizante. Para ele, "a noção de memória discursiva diz respeito à existência histórica do enunciado no interior de práticas discursivas regradas por aparelhos ideológicos [...]". O mesmo autor, em outro texto, apresenta um importante atributo da memória discursiva, qual seja, o fato de que ela se organiza verticalmente:

[...] espaço vertical, estratificado e desnivelado dos discursos [...]; séries de formulações marcando, cada uma, enunciações distintas e dispersas, articulando-se entre elas em formas linguísticas determinadas (citando-se, repetindo-se, parafraseando-se, opondo-se entre si, transformando-se...). É nesse espaço interdiscursivo, que se poderia denominar, seguindo $\mathrm{M}$. Foucault, domínio de memória, que [se] constitui a exterioridade do enunciável para o sujeito enunciador na formação dos enunciados "pré-construídos", de que sua enunciação apropriase. (COURTINE, 1999, p. 18.)

No caso do presente estudo é preciso considerar dois aspectos essenciais. Primeiro, o fato de que os objetos em causa não são enunciados verbais, mas imagéticos. Os(as) selfies, enquanto imagens que os sujeitos fazem de si e que põem a circular em redes sociais, cumprem, em certa medida, uma função enunciativo-discursiva. Segundo, o fato de estar em causa o funcionamento de uma memória específica, designada por Orlandi (2010), de "memória metálica", posto que produzida no âmbito das mídias e das novas tecnologias e, portanto, com deslocamentos conceituais e analíticos. Antes de adentrarmos a especificidade desta noção e seus respectivos deslocamentos, retomemos a afirmação de Courtine (1999) acerca da memória discursiva, enquanto organização vertical de enunciados, porque seu estatuto é o do "já-lá". Tal estatuto sustenta-se por seu pertencimento a uma determinada Formação Discursiva (FD), noção esta que é tributária de Michel Foucault ([1969] 2000, p. 43), assim descrita: 
No caso em que se puder descrever, entre um certo número de enunciados, semelhante sistema de dispersão, e no caso em que entre os objetos, os tipos de enunciação, os conceitos, as escolhas temáticas, se puder definir uma regularidade (uma ordem, correlações, posições e funcionamentos, transformações), diremos, pois, por convenção, que se trata de uma formação discursiva [...].

Ora, esta noção foi submetida, por Pêcheux ([1975] 1988), à instância ideológica, na medida em que as FDs constituem-se componentes interligados às Formações Ideológicas (FIs), Diante disso, na dispersão difusa de imagens na rede mundial não se trata apenas de uma repetibilidade enquanto enquadramento semântico-gestual que reporta um modo específico de visibilidade do eu, sobre cujas marcas discorreremos na sequência, mas de uma inscrição da memória na ordem da história pela via da ideologia.

Para compreendermos como se dá esse processo, retornemos ao já-lá a que se refere Courtine, enquanto lugar de articulação dos discursos, no sentido do fornecimento dos objetos para o sujeito, com vistas a garantir-lhe uma referência e, com isto, autorizar a predicação e a correferencialidade ([1981] 2009, p.112). Se pensarmos que o ato de registro do(a) selfie quase que necessariamente impõe o gesto de esticar o braço, pela necessidade de distanciamento do objeto eletrônico em relação ao(s) sujeito(s) a serem clicados, consequentemente, o lugar de registros/armazenamento é um "lá" virtualmente distante, lugar ausente, de desejo, que articula a vontade de presença/evidência/permanência em contraste à inevitável ausência/anonimato/fluidez/ da contemporaneidade.

A referência que Courtine ([1981] 2009) faz ao domínio de memória diz respeito a um lugar que produz estabilizações, contraposto, na sequência, a domínios de atualidade, e onde se tem o movimento inverso, porque, na instância do acontecimento, tornam-se possíveis atualizações e rupturas. Entendemos que esse "lá", reportado enquanto lugar imaginário, de desejo coletivo da contemporaneidade, figura como lugar emblemático do ponto de encontro entre o anonimato e a evidência, entre o olhar que restringe ao ângulo do eu e que expande ao ângulo do outro.

Se pensarmos essa relação e a transpormos para o funcionamento da imagem tal como ela se processa no(a) selfie, poderemos levantar vários pontos de deslizamentos dos sentidos, a partir do já discutido até aqui e também com vistas à melhor compreensão das novas formas de subjetivação.

- o plano de captação da imagem se altera;

- os objetivos do registro são outros, já que não fazem sentido sem a distribuição nas redes sociais, o que implica, necessariamente, a dimensão do outro;

- a distribuição responde à injunção por visibilidade, e isso diz respeito a um modo específico e diferenciado de subjetivação;

- o indicado anteriormente no funcionamento das formas verbais aponta uma indistinção entre sujeito e objeto, ou entre referente e referido;

- o plano de fundo perde importância ou, em outras palavras, o espaço passa por um processo de desistoricização; 
- o eu que se pretende imponente, centro e absoluto, contraditoriamente, se perde na profusão de eus que se mostram nas telas e banalizam suas imagens em cenas prosaicas e cotidianas.

Esses pontos de deslizamento, acreditamos nós, são coerentes com a noção de memória metálica trazida por Orlandi (2010), na medida em que ela se produz a partir da historicidade, conforme afirma a autora e, além disso,

\begin{abstract}
Sua particularidade é ser horizontal (e não vertical, como a define Courtine), não havendo assim estratificação em seu processo, mas distribuição em série, na forma de adição, acúmulo: o que foi dito aqui e ali e mais além vai se juntando como se formasse uma rede de filiação e não apenas uma soma, como realmente é, em sua estrutura e funcionamento. Este é um efeito - uma simulação - produzido pela memória metálica, memória técnica. Quantidade e não historicidade. Produtividade na repetição, variedade sem ruptura. E o mito, justamente, desta forma de memória é o "quanto mais, melhor". O que é discutível do ponto de vista do que chamamos memória discursiva, a constituída pelo esquecimento. Por ela, sabemos que o possível está justamente no esquecimento. (ORLANDI, 2010, p. 9)
\end{abstract}

Tomamos a última frase da citação para reforçar a nossa tese de desistoricização que está implicada na prática do(a) selfie. Os três episódios que serviram como mote para este estudo provavelmente serão esquecidos por significativa parte das pessoas, assim como tantos outros semelhantes a eles. E esse esquecimento será da ordem do cognitivo, sua permanência durará tanto quanto a efemeridade dos momentos midiáticos em que emergiram. Sem força para se constituírem como acontecimentos históricos, não ficarão sedimentados na memória coletiva, a ponto de irromperem, em épocas outras, promovendo sentidos novos.

A banalização a que nos referíamos anteriormente produz um efeito de retorno, centralismo e suposto universalismo do eu, por meio da imagem propagada ad infinitum, em razão proporcional à indistinção de eus na massa profusa da globalização. E se procurarmos entender esse processo pelo viés antropológico-cultural, respaldados pela leitura que Vargas Llosa faz em A civilização do espetáculo (2013), veremos que a massa crítica até então destinada nos espaços da interlocução pública a cientistas, compositores e filósofos está, agora, protagonizada por chefs e estilistas, também por astros e estrelas de televisão e de cinema. E mais, estão não só ocupando esses lugares, mas também exercendo influência de pensamento:

\footnotetext{
A função antes desempenhada, nesse âmbito, por sistemas filosóficos, crenças religiosas, ideologias e doutrinas, bem como por aqueles mentores da França que eram conhecidos como os mandarins de uma época, hoje é exercida pelos anônimos "diretores de criação" das agências publicitárias. (VARGAS LLOSA, 2013, p. 31)
}

Em que pese o tom elitista da tese defendida pelo autor, extraímos dele a crítica à massificação e banalização do pensamento contemporâneo, na medida em que defende, em seu arrazoado, que diante da outorga do exercício do pensar, pela cultura, ao desvão das coisas "fora de moda", e a substituição massiva das ideias por imagens - esse o ponto que nos interessa diretamente -, o público passa a carecer de defesas intelectuais e deixa de se tornar sensível aos contrabandos e extorsões de que é vítima. E, acrescentaríamos, 
ele mesmo (o público) passa a ser agente desse contrabando e dessas extorsões de que é vítima. E passa também a ser levado pelo inconsciente coletivo - vide a prática do(a) selfie.

A raiz desse processo é explicitada por Vargas Llosa (2013) a partir do ínfimo valor que o pensamento tem na chamada civilização do espetáculo. "O preço passa a se confundir com o valor de uma obra de arte", afirma ele (p. 33 e 41). A face imensa e desproporcional da pessoa, posando em frente ao Museu do Louvre, apenas de passagem, por exemplo, registra para o outro seu poder (econômico e simbólico) para chegar lá. Pouco importa se acessou a criação estética ou os séculos de arte comportados naquele espaço, o valor da arte, enfim.

E quando acessa, nem sempre o objetivo é a fruição e/ou contemplação. Veja-se, por exemplo, os registros de uma das mais famosas telas do Louvre, a Mona Lisa, de Leonardo da Vinci (1503). Não raro, trata-se de um aglomerado de mãos estendidas para cima, em desesperado esforço para captar a imagem. E, no relato aos amigos que do lado de cá do oceano ficaram, a decepção diante do imaginado x realidade: "era um quadro minúsculo!"

Retornando à sobreposição do preço em detrimento do valor da arte e do conhecimento em geral, acrescentamos nós, pergunta-se: e de parte dos sujeitos, como se dá esse processo de captura, que os faz responder afirmativamente ao conjunto de injunções que se lhes impõem na sociedade contemporânea? E, de outra parte, não disjunta desta, que mecanismos são histórica e politicamente construídos para que se justifique o processo de captura? Do que estamos falando: atente-se para o modo como a prática do(a) selfie emergiu como justificativa mais do que aceitável no caso dos "cadeados do amor", na Pont des Arts, em Paris. E com o argumento de que o peso dos cadeados que os milhares de casais emblematicamente colocam na ponte estava lhe gerando danos físicos com risco, inclusive, de ruir, a prefeitura de Paris substituiu a grade de ferro por painéis de vidro e sugeriu que no lugar dos cadeados os casais passassem a fazer selfies ${ }^{7}$. Trata-se, em nosso entendimento, de uma sobreposição da ordem do público sobre a do privado, o que gera um efeito de incapacidade de discriminação de parte dos sujeitos em relação à função da exposição imagética, em que pese a legitimidade dos argumentos apresentados. $\mathrm{Ou}$, em outros termos, trata-se da dimensão política da questão, haja vista que não se está mais diante de uma questão que é da ordem do individual, atravessada por razões econômicas e históricas e equacionadas na ordem do coletivo que, contraditoriamente, apaga a possibilidade de os sujeitos colocarem-se politicamente em sua prática histórica.

\section{ALGUMAS BREVES CONSIDERAÇÕES FINAIS}

A reflexão ora desenvolvida tomou como mote sujeitos em práticas concretas, três cenas recortadas do quotidiano e pensou-as enquanto materialidades históricas

\footnotetext{
7 Fonte: Jornal online BBC. Disponível em: <http://www.bbc.co.uk/portuguese/noticias/2014/09/140921_paris_cadeados_ponte_df_cc>. Acesso em: 30 set. 2014.
} 
produzindo sentidos a partir do nome da prática que as representa - a designação, demarcando o contraditório apagamento dos sujeitos produzidos pela estranha simbiose agente-paciente na produção das imagens. Também trabalhou a relação que as imagens feitas alcança com a memória histórico-social, igualmente na perspectiva de uma impossibilidade de fixação.

"O real é impiedoso", já afirmava Pêcheux (2008, p. 35), falando acerca da Lei e sobre a necessidade de o sujeito assenhorear-se das coisas-a-saber para não ser pego no absoluto desconhecimento delas. $\mathrm{O}$ ato diário e contínuo de imersão nas redes sociais tem construído/imposto para e pelos sujeitos um real que lhes diz sobre a necessidade imperiosa de lá se fazerem presentes, sob pena de não existirem. Esta a lei em sentido simbólico. E os limites entre o imaginário e as condições de verdade dessa construção se esvanecem sob os olhos de seus próprios assinantes. Este o próprio do funcionamento da ideologia. Impiedosa ironia que traga os sujeitos, impedindo-os, muitas vezes, de resistirem ou de romperem com o círculo.

Contudo, aprendemos também da leitura que Pêcheux fez de Lacan, que "não há ritual sem falhas" (PÊCHEUX, [1975] 1988, p. 301). Que se manifesta pela contradição latente no próprio mecanismo de injunção, o qual, de um lado, chama para estar lá, como condição de visibilidade, porém, sem nenhuma garantia da promessa anunciada. E, de outro lado, ao mesmo tempo em que ordena a colocação dos sujeitos nos pontos e postos de visibilidade, escorraça-os, como pudemos ver nos recortes aqui trazidos.

A prática da selfie, circunscrita em processos protagonizados por sujeitos que são fruto de um tempo e de seus embates, sintetiza a indistinção que se produz entre sujeito e objeto, embora os atores das três cenas motivadoras do debate se pensem como protagonistas. Como se a ordem do individual pudesse sobrepujar a das coletividades históricas. E nisso a contradição na ordem da subjetivação. O desvario de imagens desistoricizadas, ou de uma memória volatizada em uma massa homogeneizada pela profusão da repetibilidade, pela banalização. Instante efêmero que demanda captura para satisfazer a suposta necessidade do olhar-outro coletivo. Anônimo. Indefinido. Gesto de captura de imagens no qual contraditoriamente o sujeito se funde com o objeto, e assim se coisifica. Paradoxalmente, porém, lhe é interditado ficar invisível, e os espaços os quais lhe são dados para "mostrar-se" não são mais que o anonimato contínuo. Esse sujeito do qual vimos falando não se produz a si próprio, como quer parecer, ao contrário, é ele partícipe de processos históricos que poderiam compor lugares de resistência, mecanismos de defesa, nos termos de Claudine Haroche, contudo, tende a responder positivamente aos apelos para que se mostre. O paradoxo da contemporaneidade é tão cruel que a alguns é dada a possibilidade de resistir. Sebastião Salgado, cujo nomememória, por si só, já convoca outros a que se mostrem a seu lado, pode "escolher" não querer aparecer. Já a moça-anônima que o "agarrou para tirar selfie" "precisa aparecer" e, de preferência, ao lado de alguém que a retire do anonimato. Fica, assim, posto algo a se pensar: como constituir, pois, esses espaços de resistência ante a tirania da visibilidade? Ou, nos termos de Boaventura dos Santos: como prover aquilo que mais falta no transbordante de uma enchente: “água potável”?

\footnotetext{
${ }^{8}$ Comunicação pessoal em Conferência na UFRGS, em 05/09/2014, intitulada "As epistemologias do Sul e as ciências sociais do futuro".
} 
ALTHUSSER, L. [1970] Aparelhos ideológicos de estado: nota sobre os aparelhos ideológicos de estado. 9. ed. Rio de Janeiro: Edições Graal, 2003.

AUBERT, N.; HAROCHE, C. Les tyrannies de la visibilité: être visible pour exister? Paris: Érès, 2011.

COURTINE, J.-J. [1981]. Análise do discurso político: o discurso comunista endereçado aos cristãos. São Carlos: EduFSCar, 2009.

COURTINE, J.-J. [1981]. O Chapéu de Clémentis. In: INDURSKY, F.; LEANDRO FERREIRA, M.C. (Org.). Os múltiplos territórios da Análise de Discurso. Porto Alegre, Ed. Sagra Luzzatto, 1999.

FOUCAULT, Michel [1969]. A arqueologia do saber. Rio de Janeiro: Forense Universitária, 2000.

GOFFMAN, E. Interaction ritual: essays on face-to-face behavior. New York: Doubleday Anchor, 1967.

GRIPP, M. R. S. Recusas a convites no português de universitários curitibanos e cariocas. 2015. $238 \mathrm{f}$.

Tese (Doutorado em Letras) - Programa de Pós-graduação em Letras, Universidade Federal do Paraná, Curitiba, 2015.

NUNES, J. H. Dicionários: história, leitura e produção. Revista de Letras, Taguatinga, v. 3, p. 6-21, 2010.

ORLANDI, E. P. Análise de Discurso: princípios \& procedimentos. Campinas: Pontes, 2009a.

Língua brasileira e outras histórias: discurso sobre a língua e ensino no Brasil. Campinas: Editora RG, 2009b.

A contrapelo: incursão teórica na tecnologia - discurso eletrônico, escola, cidade. RUA,

Campinas, v. 2, n. 16, p. 5-17, nov. 2010. Disponível em:

<http://www.labeurb.unicamp.br/rua/pages/home/lerArtigo.rua?pdf=1\&id=91>. Acesso em: 30 set. 2014. PÊCHEUX, M. [1975]. Semântica e discurso: Uma crítica à afirmação do óbvio. Campinas, SP: Editora da Unicamp, 1988.

[1983]. O discurso: estrutura ou acontecimento. Tradução de Eni P. Orlandi. Campinas (SP): Pontes, 2008

SAVILLE-TROIKE, M. The ethnography of communication: An introduction. $3^{\text {rd }}$ ed. Oxford: Blackwell Publishing, 2003.

VARGAS LLOSA, M. A civilização do espetáculo. Tradução de Ivone Benedetti. Rio de Janeiro:

Objetiva, 2013.

Jornal online BBC. Disponível em:

<http://www.bbc.co.uk/portuguese/noticias/2014/09/140921_paris_cadeados_ponte_df_cc>. Acesso em: 30 set. 2014.

$<$ http://oglobo.globo.com/brasil/selfie-em-velorio-de-campos-gera-indignacao-nas-redes-sociais13635476>. Acesso em: 25 set. 2014.

<http://www1.folha.uol.com.br/ilustrada/2014/09/1517385-selfie-e-agressao-permanente-diz-sebastiaosalgado.shtml>. Acesso em: 30 set. 2014.

<http://www.priberam.pt/dlpo/selfie>. Acesso em: 30 set. 2014.

Recebido em: 18/09/15. Aprovado em: 06/01/16.

Title: The practice of the selfie and the ways of subjectivity in contemporaneity

Author: Gesualda dos Santos Rasia

Abstract: Affiliated to the French DA, this study is concerned about contemporary injunction to the visibility sharpened by virtual dimension. In order to think about the ways like weave the called to exposure of self, we bring as theme the selfie made by a girl smiling at the funeral of Eduardo Campos, candidate to the Presidency of Brazil; she was next to his coffin, in August, 2014, fact which gave negative repercussion at that time. This happening is put in relation to other from similar nature, but different in scope, and subjected to discursive memory notion to register how the subjectivity's ways are created or recreated. The theoretical discussion weaved allows to converge three dimensions relative to the practice of the selfie, raised by episodes taken as motivators of debate: the linguistic dimension as historical materiality; the anthropologic as practice by subjects inscribed socially; and lastly, the politics, because it is full of meanings and permeated by ideology.

Keywords: Subjectivity. Discursive memory. In(visibility). Selfie. 
Título: La práctica del selfie y modos de subjetivación en la contemporaneidad

Autor: Gesualda dos Santos Rasia

Resumen: Ese estudio, alineado con el AD francesa, se ocupa con la determinación contemporánea de la visibilidad, agudizada por la dimensión virtual. Para reflexionar sobre las maneras como se teje el llamado a la exposición del yo, partimos de la selfie hecha por una chica, sonriendo, en el funeral del candidato a presidente en Brasil Eduardo Campos, al lado de su ataúd, en agosto de 2014, fato de repercusión negativa en aquél tiempo. Este acontecimiento es puesto en relación con otros, de naturaleza semejante, pero de alcance diferenciados, como mote para discusión central del estudio: cómo se (re)configuran hoy las formas de subjetivación delante de lo que comprendemos como la pérdida de la característica histórica de la memoria. La discusión teórica desarrollada hace convergir tres dimensiones atinentes a la práctica del selfie, suscitadas por los episodios tomados como motivadores del debate: la dimensión lingüística, mientras la materialidad histórica; la antropológica, como práctica asumida por sujetos socialmente inscritos; y la política, porque revestida de sentidos y ocurre a través de la ideología.

Palabras-clave: Subjetivación. Memoria discursiva. In(visibilidad). Selfie. 